\title{
Penggunaan Modul Kimia Berbasis Problem Based Learning (PBL) untuk Meningkatkan Hasil Belajar Siswa
}

\author{
Eva Nursa'ban', Ewisahrani ${ }^{2}$, Fathurrahmaniah ${ }^{3}$ \\ ${ }^{123}$ Program Studi Pendidikan Guru Sekolah Dasar STKIP HARAPAN BIMA, Indonesia \\ Email Correspondent: evanursaban@gmail.com
}

\begin{abstract}
Abstrak. Fokus penelitian ini mengenai penggunaan modul kimia. Tujuan penelitian ini untuk mengetahui peningkatan hasil belajar siswa sebagai akibat dari pembelajaran PBL. Penelitian ini merupakan deskriptif kuantitatif dengan penarikan kesimpulan melalui analisis statistik. Sampel yang diambil adalah kelas XI IPA SMA Negeri 3 Wera. Instrumen penelitian yang digunakan adalah efektivitas posttest yang dilaksanakan setelah pemberian perlakuan. Data hasil analisis penelitian diperoleh skor rata-rata prettest 33,33 dan skor rata-rata posttest 79,77 dan ditunjuk juga dari hasil nilai rata-rata gain sebesar 0,68 dengan kategori sedang. Hasil uji t diperoleh nilai sebesar $0,000<0,05$ maka $\mathrm{H}_{\mathrm{a}}$ diterima, artinya terdapat pengaruh yang signifikan antara prettest dan posttest. Berdasarkan temuan tersebut dapat disimpulkan bahwa modul kelarutan dan hasil kali kelarutan berbasis problem based learning berpengaruh terhadap hasil belajar siswa. Berdasarkan hasil analisis tersebut diperoleh 1) terdapat peningkatan dengan menggunakan modul PBL, 2) terdapat peningkatan hasil belajar siswa dengan menggunakan model PBL, 3) peningkatan hasil belajar siswa dengan menggunakan model PBL lebih baik daripada menggunakan model konvensional, 4) terdapat factor pendukung dan penghambat dalam meningkatkan hasil belajar siswa.
\end{abstract}

Kata kunci: Modul, Problem Based Learning, Hasil Belajar Siswa

\section{PENDAHULUAN}

Peningkatan hasil belajar siswa tentunya tidak terlepas dari pengalaman belajar yang dialami oleh siswa sebagai suatu proses belajar. Proses belajar adalah suatu proses mendapatkan pengetahuan yang melibatkan pendidik dan para siswa di intitusi pendidikan yang melibatkan aspek kognitif, psikomotorik, dan afektif. Proses belajar akan berjalan sebagaimana mestinya jika siswa ikut aktif dalam belajar. Pemilihan pengalaman belajar mengarah pada bagaimana mengaktifkan siswa dalam mempelajari materi kimia.

Pemilihan pengalaman belajar bagi siswa merupakan salah satu tugas guru sebagai fasilitator yang bertugas menyediakan lingkungan belajar bagi siswa. Ketidaksesuaian metode yang dipilih oleh guru dalam pembelajaran akan berdampak pada hasil belajar siswa. Hal ini terjadi di sekolah-sekolah, salah satunya SMA Negeri 3 Wera, dari data perolehan nilai yang diberikan oleh salah seorang guru bidang studi Kimia memperlihatkan bahwa persentase ketuntasan siswa hampir di setiap kelas kurang dari $70 \%$. Data menunjukkan bahwa kelas XI IPA yang terdiri dari 31 siswa, sekitar 64\% (20 siswa dari 31 siswa) sudah tuntas belajar dengan nilai minimum 75 sedangkan 36\% (11 siswa dari 31 siswa) sisanya tidak tuntas belajar.

Upaya untuk menciptakan suasana pembelajaran kondusif dan menyenangkan perlu adanya pembelajaran yang menarik. Siswa tidak merasa terbebani dengan materi yang harus dikuasai. Jika siswa sendiri yang mencari, mengolah dan menyimpulkan atas masalah yang dipelajari maka pengetahuan yang didapatkan akan lebih lama melekat dipikiran. Guru sebagai fasilitator memiliki kemampuan dalam memilih metode pembelajaran yang efektif untuk meningkatkan kemampuan berpikir siswa. Dengan inovasi metode pembelajaran diharapkan akan tercipta suasana belajar aktif dan siswa mudah 
menguasai materi. Salah satu metode pembelajaran yang memberdayakan siswa adalah metode Problem Based Learning (PBL). Metode yang menantang siswa bekerja sama dalam kelompok mencari solusi dari masalah dengan mengaitkan rasa keingintahuan serta analisis siswa untuk berpikir kritis dan analitis (Amir, 2009). Diharapkan siswa dalam pembelajaran lebih efektif, lebih aktif dan mampu menerima pelajaran dalam memahami materi. Pembelajaran berdasarkan masalah digunakan untuk merangsang berpikir tingkat tinggi dalam situasi berorientasi masalah, termasuk di dalamnya belajar bagaimana belajar (Kunandar, 2009). Rata-rata hasil belajar siswa yang diajarkan dengan model PBL lebih tinggi daripada hasil belajar siswa dengan menggunakan model pembelajaran konvensional, sedangkan penelitian, menunjukkan bahwa PBL merupakan strategi yang bermanfaat dan menyenangkan. PBL juga menempatkan siswa sebagai pusat dari proses belajar yang akan meningkatkan pengetahuan, keterampilan dan pemahaman.

Modul sebagai bahan belajar mandiri tanpa bimbingan guru berisi tentang petunjuk belajar (petunjuk siswa dan guru), kompetensi yang akan dicapai, conten atau isi materi, informasi pendukung, latihan-latihan, petunjuk kerja dapat berupa lembar kerja, evaluasi, dan balikan terhadap hasil evaluasi. Modul sains di pelajari peserta didik agar peserta didik menguasai sains dan kemampuan berikut.Pertama, peserta didik menguasai produk sains, seperti konsep-konsep.Kedua, peserta didik dapat menggunakan metode ilmiah untuk memecahkan masalah sains. Ketiga, peserta didik memiliki nilai yang berkaitan dengan masalah sikap setelah biasa mempelajari dan menguasai produk dan menguasai produk dan proses sains.

Belajar berbasis masalah (Problem Based Learning). PBL merupakan suatu strategi untuk menampilkan situasi dunia nyata yang signifikan, terkontekstual, dan memberikan sumber, bimbingan, dan petunjuk pada pembelajar saat mereka mengembangkan isi pengetahuan dan ketrampilan memecahkan masalah. Dalam PBL mahasiswa bekerja sama untuk mempelajari isu suatu masalah sambil mereka merancang suatu pemecahan masalah yang dapat dilakukan. Tidak seperti pembelajaran tradisional, yang sering dilakukan dalam format kuliah, pembelajaran dengan PBL biasanya terjadi dalam kelompok diskusi kecil mahasiswa yang difasilitasi oleh tutor (De Gallow, 2006).

Masalah-masalah yang digunakan untuk PBL harus ditujukan pada tujuan kurikulum, nyata dan dapat dikerjakan, memancing keingintahuan peserta didik, menempatkan kelompok dalam peran professional (sebagai ilmuwan), mengharuskan mahasiswa untuk mengembangkan strategi pemecahan masalah, mengkondisikan mahasiswa untuk menguasai pengetahuan baru, dan mengharuskan peserta didik membuat keputusan, perkiraan, dan pencocokan informasi yang harus dihilangkan atau berlebihan.

\section{METODE PENELITIAN}

Jenis penelitian yang digunakan adalah deskriptif kuantitatif dengan penarikan kesimpulan melalui analisis statistik. Data yang dikumpulkan selanjutnya dianalisis menggunakan analisis statistik deskriptif .selain itu data hasil penelitian juga dianalisi menggunakan analisis uji dua sampel independen dan uji t untuk menguji hipotesis penelitian. Sebelum dilakukan pengujian hipotesis, terlebih dahulu dilakukan uji normalitas dan uji homogenitas dengan menggunakan program SPSS 18 for windows. Data hasil belajar siswa dikumpulkan dengan istrumen berbentuk pilihan ganda sebanyak 15 soal. Sebelum digunakan dalam penelitian, instrumen penelitian terlebih dahulu diujicoba. Terdapat beberapa langkah validasi terhadap instrumen meliputi validasi isi oleh pakar kimia, analisis butir tes, analisis tingkat kesukaran, analisis daya pembeda, dan analisis reliabilitas dengan menggunakan Software 
Jurnal Ilmu Sosial dan Pendidikan

http://ejournal.mandalanursa.org/index.php/JISIP/index

Terakreditasi Peringkat 5 (No. SK: 85/M/KPT/2020)

Quest.Sedangkan untuk mengetahui efektifitas dalam pembelajaran berbasis PBL menggunakan gain score ternormalisasi untuk prettest dan posttest.

\section{HASIL PENELITIAN DAN PEMBAHASAN}

Hasil studi pustaka merupakan hasil analisis dari KI-KD pembelajaran kimia pada kelas XI SMA yang mengacu kepada standar isi (permendikbud nomor 64 tahun 2013 tentang standar isi pendidikan dasar dan menengah). Hasil analisis ini ditujukan untuk menentukan kompetensi inti, kompetensi dasar dan materi pembelajaran yang memungkinkan untuk sebagai acuan pengembangan modul pembelajaran.

Penelitian ini menganalisis data dengan analisis statistik deskriptif dan uji hipotesis dengan uji t. Data dalam penelitian ini adalah data yang terdiri dari rata-rata gain, uji normalitas, homogenitas dan uji t. Rangkuman data hasil tes dengan analisis deskriptif disajikan dalam tabel berikut.

Tabel 1. Rata-rata nilai gain untuk kelas kontrol dan eksperimen

\begin{tabular}{|l|c|c|c|c|c|}
\hline Tes & $\begin{array}{l}\text { Jumlah } \\
\text { Siswa }\end{array}$ & Mean & $\begin{array}{l}\text { Nilai } \\
\text { Min }\end{array}$ & $\begin{array}{l}\text { Nilai } \\
\text { MaX }\end{array}$ & N Gain \\
\hline \multicolumn{7}{|c|}{ KELAS KONTROL } \\
\hline Prettest & 31 & 33 & 20 & 60 & \multirow{2}{*}{0,65} \\
\hline Posttest & 31 & 78 & 70 & 90 & \multirow{2}{*}{0,68} \\
\hline \multicolumn{7}{|c|}{ KELAS EKSPERIMEN } \\
\hline Prettest & 31 & 33 & 20 & 60 & 93 \\
\hline
\end{tabular}

Berdasarkan tabel. 1 nilai dari hasil hitungan Prettest dan Posttest pada siswa kelas kontrol dan eksperimen dilihat dari nilai ratarata lebih besar nilai eksperimen yang menggunakan modul problem based learning dengan ini menyatakan bahwa dapat meningkatkan hasil belajar siswa.

Tabel 2. Deskripsi hasil data siswa

\begin{tabular}{|c|c|c|c|}
\hline Kelas & Jumlah Siswa & Mean & Standar Deviasi \\
\hline \multicolumn{4}{|c|}{ SMA Negeri 3 Wera } \\
\hline Kontrol & 31 & 75,94 & 7,40 \\
\hline Eksperimen & 31 & 78,77 & 6,56 \\
\hline
\end{tabular}

Berdasarkan tabel 2 menyajikan data hasil belajar kognitif siswa dilihat dari nilai posttest kelas kontrol dan eksperimen yang diberikan pembelajaran menggunakan modul
Vol. 5. No. 2 Maret 2021

p-ISSN: 2598-9944 e- ISSN: 2656-6753

yang telah dikembangkan yaitu modul pembelajaran kimia berbasis problem based learning (PBL) pada materi kelarutan dan hasil kali kelarutan (Ksp) dan yang tidak menggunakan modul. Hasil pembelajaran kelas kontrol pada SMA N 3 Wera diperoleh adalah 75,94 dengan standar deviasi 7,40. Sedangkan untuk kelas eksperimen diberi pembelajaran dengan modul yang dikembangkan, hasil ratarata yang diperoleh siswa adalah 78,77 dengan standar deviasi 6.56. Melihat nilai rerata dari kelas kontrol dan eksperimen dari tiga sekolah tersebut pada Tabel 2 dapat diketahui bahwa modul kimia berbasis PBL pada materi kelarutan dan hasil kali kelarutan dapat meningkatkan hasil belajar siswa.

Analisis data yang digunakan adalah hasil tes pengetahuan materi kelarutan dan hasil kali kelarutan yang diukur melalui pretest dan posttest pada kelas pengujian produk. Hasil pretest dan posttest diuji gain score untuk mengetahui efektifitasnya dan dengan menggunakan program SPSS 18 for windows menggunakan one sample $t$ test untuk mengetahui perbedaannya hasil belajar siswa. Sebelum dilakukan uji hipotesis data siswa di analisis menggunakan uji prasyarat yaitu uji normalitas, uji homogenitas dan di lanjutkan dengan uji t.

Tabel 3. Uji normalitas

One-Sample Kolmogorov-Smirnov Test

\begin{tabular}{|ll|r|r|}
\hline \multicolumn{2}{|c|}{ One-Sample Kolmogorov-Smirnov Test } \\
\hline N & \multicolumn{1}{|c|}{ KONTR } & EKSPERIMEN \\
Normal & Mean & 31 & 31 \\
Parameters & 75,9355 & 81,1290 \\
Most Extreme & Std. Deviation & 7,40241 & 7,80915 \\
Differences & Absolute &, 203 &, 235 \\
& Positive &, 203 &, 235 \\
Kolmogorov-Smirnov Z &,- 160 &,- 162 \\
Asymp. Sig. (2-tailed) & 1,128 & 1,308 \\
a. Test distribution is Normal. &, 157 &, 065 \\
b. Calculated from data. & & \\
\hline
\end{tabular}

Berdasarkan tabel 3 hasil Analisi data diperoleh hasil uji normalitas untuk data kelas control sebagai berikut : signifikansi sebesar $0,157>0,05$ maka disimpulkan nilai kelas kontrol siswa terdistribusi normal. Berdasarkan hasil Analisi data diperoleh hasil uji normalitas untuk data kelas eksperimen sebagai berikut : signifikansi sebesar $0,065>0,05$ maka 
Jurnal Ilmu Sosial dan Pendidikan

http://ejournal.mandalanursa.org/index.php/JISIP/index

Terakreditasi Peringkat 5 (No. SK: 85/M/KPT/2020)

disimpulkan nilai kelas eksperimen siswa terdistribusi normal.

Tabel 4 uji homogenitas

Test of Homogeneity of Variances

\begin{tabular}{|r|r|r|r|}
\hline $\begin{array}{r}\text { Levene } \\
\text { Statistic }\end{array}$ & \multicolumn{1}{|c|}{ df1 } & \multicolumn{1}{c|}{ df2 } & Sig. \\
\hline 2,898 & 3 & 27 &, 053 \\
\hline
\end{tabular}

Berdasarkan hasil analisis diperoleh hasil uji homogenitas kelas kontrol dan eksperimen sebagai berikut : 0,053 >0,05 maka dapat disimpulkan nilai kontrol dan eksperimen variansinya homogen

Tabel 5. Uji t

\begin{tabular}{|rl|r|r|r|r|}
\hline \multicolumn{2}{|c|}{ Group Statistics } \\
\hline \multirow{2}{*}{ NILAI } & \multicolumn{1}{|c|}{$\mathrm{N}$} & Mean & Std. Deviation & $\begin{array}{c}\text { Std. Error } \\
\text { Mean }\end{array}$ \\
& 1 KONTROL & 31 & 75,94 & 7,402 & 1,330 \\
& 2 EKSPERIMEN & 31 & 81,13 & 7,809 & 1,403 \\
\hline
\end{tabular}

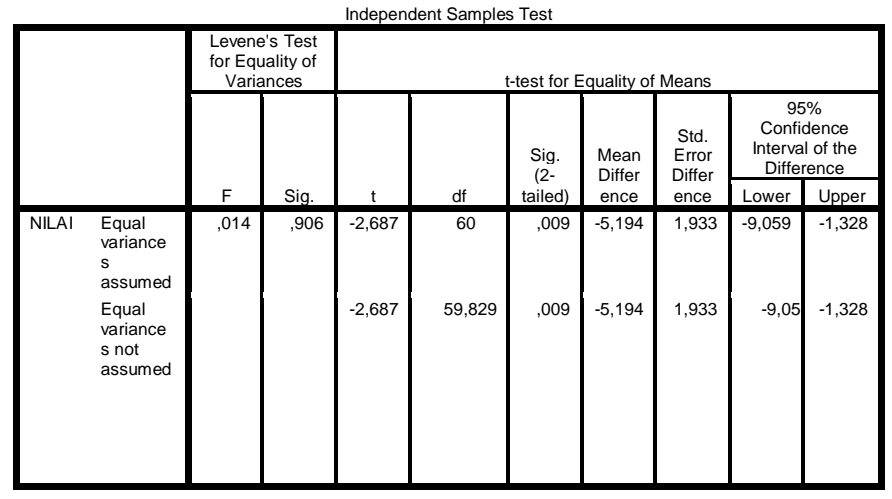

Berdasarkan hasil uji t diatas diperoleh signifikasi sebesar $0,009<0,05$, sehingga dapat ditarik kesimpulan bahwa ada perbedaan yang signifikan antara nilai pada kelas kontrol dan eksperimen yang menggunakan produk modul pembelajaran yang dikembangkan. Hal ini menunjukkan bahwa modul yang dikembangkan efektif untuk dijadikan bahan dalam proses pembelajaran, sehingga dapat ditarik kesimpulan bahwa ada pengaruh yang signifikan antara nilai posttest siswa yang menggunakan produk modul yang dikembangkan. Sedangkan analisis untuk mengetahui keefektifan dalam pembelajaran menggunakan gain score ternormalisasi untuk pretest dan posttest pengujian produk. Berdasarkan perhitungan gain score untuk
Vol. 5. No. 2 Maret 2021

p-ISSN: 2598-9944 e- ISSN: 2656-6753

kelas pengujian produk termasuk kategori tinggi (Meltzer, 2002:1260).

\section{KESIMPULAN}

Dari hasil data diatas dapat disimpulkan bahwa dengan menggunakan modul kimia berbasis pbl dapat meningkat hasil belajar siswa di lihat dari kelas kontrol yang tidak menggunakan modul dengan kelas eksperimen yang menggunakan modul.

\section{Saran}

Berdasarkan hasil penelitian diatas didapatkan beberapa syarat yaitu, 1 . Penggunaan dan pengembangan modul pembelajaran kimia sma berbasis problem based learning (PBL) terintegrasi pendidikan karakter disarankan dimanfaatkan secara optimal oleh peneliti lain sebagai contoh dalam menyusun modul pembelajaran dengan materi pembelajaran lain dan jenjang yang berbeda. 2 . Penggunaan modul pembelajaran dalam kelas harus memperhatikan alokasi waktu dan manajemen yang baik agar semua perencanaan dapat dilakukan secara optimal.

\section{DAFTAR PUSTAKA}

Akcay, B. (2009). Problem-based learning in science education. Journal of Turkish Science Education, 6(1), 26-36. Retrieved from https://www.pegem.net/dosyalar/ dokuman/48116-2009042911493104problem-based-learning-in-scienceeducation.pdf

Amir. 2009. Inovasi Pendidikan Melalui Problem Based Learning: Bagaimana Pendidik Memberdayakan Pemelajar di Era Pengetahuan. Jakarta: Kencana Prenada Media Group

Bilgin, Ibrahim, et al. 2008. "The Effect of Problem-Based Learning Instruction on University Students' Performance of Conceptual and Quantitative Problems in Gas Concepts".University of Mustafa Kemal, Gaziosmanpasa University, Atarturk University, 
Turkiye.Eurasia Journal of Mathematics, Science \& Technology Education, 2009, 5 (2), 153-164. EISSN: 1305-8223. ejmste.com/v5n2/Eurasia_v5n2_Bilgin _etal.pdf.

Eva, N, Mohammad, M \& Sry, Y (2018) Pengaruh Pembelajaran Kimia Berbasis Problem Based Learning (Pbl) Dalam Meningkatkan Hasil Belajar. Lembaga Penelitian Dan Pendidikan (LPP) Mandala . Prosiding Seminar Nasional p-issn 2623-0291 eissn 2623-2774.

DOI: http://dx.doi.org/10.1234/.v0i0.3 $\underline{98}$

Eva, N, Mohammad, M \& Sry, Y (2019). Improving Student Learning Outcomes In Science Subjects Through The Implementation Of Pbl-Based Module. JPBI (Jurnal Pendidikan Biologi Indonesia) p-issn 2442-3750, e-issn 2537-6204 // vol. 5 no. 2 july 2019, pp. 269-276. DOI: https://doi.org/10.22219/jpbi.v5i2.753 $\underline{4}$

Herman. Dwi Surjono. 2013. Pengaruh Problem Based Learning Terhadap Hasil Belajar Ditinjau dari Motivasi Belajar PLC di SMA. Jurnal Pendidikan Vokasi, Vol.3, No. 2

Kunandar. 2009. Guru Profesional Implementasi Kurikulum Tingkat Satuan Pendidikan (KTSP) dan Sukses dalam Sertifikasi Guru. Jakarta: Rajawali Pers

Meltzer, D.E. 2002. The relationship between mathematics preparation and conceptual learning gainsin physics: a possible "hidden variable"in diagnostic pretest scores. Departement of psysics a and anstronomy, lowa state university, ames, lowa 50011.am. J. Phys, vol 70, no 12, halaman 12591268. 